Daimon. Revista Internacional de Filosofía, Suplemento 5 (2016), 515-519

ISSN: 1130-0507 (papel) y 1989-4651 (electrónico)

http://dx.doi.org/10.6018/daimon/268581

\title{
Miradas desenfocadas
}

\author{
Unfocused looks
}

\section{LAURA GARCÍA GARRIDO*}

\begin{abstract}
Resumen: En este trabajo se expresa una vinculación entre cuerpo y moda. Para ello, mediante una mirada interna propia, se comprende cómo un individuo puede realizar un autoanálisis de su cuerpo. Además, elaborando una mirada externa ajena se busca acceder a las concepciones que otros tienen sobre nosotros. Por último, se presta atención al espacio del "centro comercial" donde ambas miradas convergen. Para concluir, se hace una llamada a la importancia de re-pensar el cuerpo, con el objetivo de llegar a ser más conscientes de la necesidad de obtener armas de pensamientos útiles para encontrar el bienestar propio y ajeno.
\end{abstract}

Palabras clave: mirada, cuerpo, moda, imagen, centro comercial, apariencia.

\begin{abstract}
In this text you may read about a link between body and fashion. You are able to understand how a person can do a self-analysis about your body through an internal look by yourself. Using an external look, you find other point of view in relation to yourself. Finally, you pay attention to the space of the "shopping centre" where two looks can exist together. In conclusión, you expose the value of thinking about our body again, with the aim of becoming more aware about the need to obtain thinking weapons to achieve an essential wellness.
\end{abstract}

Keywords: look, body, fashion, image, shopping centre, appearance.

\section{Introducción}

El discurso que nos ocupa se basa en la relación entre cuerpo y moda. En el terreno filosófico,

cabe referirse más bien a la corporeidad que al cuerpo, pensando la corporeidad como una importante categoría derivada, tan dependiente en su forma de las dinámicas relacionales y las modalidades abstractas, como en su contenido de las caricias y de las sombras de las miradas de los otros cuerpos. ${ }^{l}$

Fecha de recepción: 30/05/2016. Fecha de aceptación: 06/09/2016.

* Universidad de Granada. Licenciada en Filosofía, Máster en Filosofía Contemporánea y Máster en Profesorado de Educación Secundaria Obligatoria y Bachillerado, Formación Profesional y Enseñanza de Idiomas. Dirección de correo electrónico: lgarci@correo.ugr.es. Líneas de investigación: Filosofía Española y Filosofía de la Educación.

1 Biedma, J. (2001): Cuerpo fugaz, A Parte Rei: revista de filosofía, 14, pp. 1. En: http://serbal.pntic.mec. es/ cmunoz11/cuerpobied.pdf 
Una vez citado lo anterior, se establecen dos perspectivas: la mirada interna propia, la de cada uno con su sí mismo hacia su cuerpo, con la visión de su imagen corporal; y la mirada externa ajena o mirada del otro hacia el cuerpo, como mercancía que se oferta y expone, buscando el encuentro de la belleza impuesta por la apariencia de la moda.

A continuación, la reflexión se deriva hacia un lugar concreto, la figura del centro comercial, entendido como espacio intermedio entre la calle (área pública) y la casa donde habitamos (área privada).

Por último, y como conclusión, se estima la necesidad de re-pensar el cuerpo en nuestra sociedad avanzada y compleja, con el propósito de hacer del individuo un ser consciente, tanto de sí mismo como de los demás, proporcionando armas de pensamiento que erradiquen con la formación de individuos des-armados y des-almados.

\section{La mirada interna propia: la imagen corporal}

El cuerpo, en forma y contenido es una materia constituida por diferentes partes determinando una apariencia física. Sin embargo, la imagen corporal es la representación del cuerpo que cada persona construye en su mente y la vivencia que tiene del propio cuerpo. De esta manera la apariencia física se convierte en la primera fuente de información en la interacción social. Por su parte la imagen corporal va más allá, porque mediante su visión, la persona percibe, evalúa, valora, vive su propio cuerpo como un todo en el que entra a formar parte de su personalidad y su bienestar psicológico.

Entendemos que, "la imagen corporal va construyéndose evolutivamente. Así, en diferentes etapas de la vida vamos interiorizando la vivencia de nuestro cuerpo, [...]." ${ }^{2}$ Por tanto, por encima de la mera apariencia física nos encontramos con la forma en la que uno propiamente se siente, percibe, imagina, actúa, etc. con respecto a su propio cuerpo.

Cuando la preocupación e insatisfacción por el cuerpo no son acordes a la realidad, y ocupan la mente con mucha frecuencia e intensidad, generando además malestar que interfiere en la vida cotidiana, se habla de trastorno de la imagen corporal. Lo cual nos lleva al siguiente punto en la medida en que entran en juego las percepciones del otro.

\section{La mirada externa ajena: la apariencia de la moda}

La moda propone unos ideales estéticos en los cuales se relaciona lo bello con lo bueno, pero esta relación no siempre se cumple. Tanto a nivel socio-cultural como familiar, se modelan figuras idealizadas que incorporan actitudes, esquemas, ideales, percepciones y emociones sobre el cuerpo. Así, la persona vulnerable puede sufrir críticas o burlas hacia el cuerpo por parte del grupo de iguales.

Resulta curioso como ya Lewis Carroll, antes de que su personaje ficticio de Alicia se adentrara en el País de las Maravillas, apuntara a esta idea afirmando que

2 Salaberria, K.; Rodríguez, S. y Cruz, S. (2007): Percepción de la imagen corporal, Osasunaz, 8, pp. 172. En: http://www.euskomedia.org/PDFAnlt/osasunaz/08/08171183.pdf 
nunca podremos saber si la vida al otro lado del espejo es, en realidad, la nuestra o sólo la pura tendencia imitativa de unos seres sin alma que nos clavan la mirada cuando les acercamos el rostro, que sonríen si abrimos la boca y que nos devuelven una mueca amarga al preguntarles qué pasó con el niño que hace dos días se miraba al cristal. ${ }^{3}$

Como vemos, el cuerpo se convierte en el centro de las miradas de los otros, como una mercancía que tiene características de oferta, de exposición, de deseo, e incluso de adoración. Estas miradas se construyen en el espacio público y en las relaciones sociales. La moda se convierte en un mercado, donde los maniquíes o modelos semejan personas con un ideal de belleza, ataviadas con todo tipo de adornos.

Es aquí, en la visión externa donde los patrones de moda cobran presencia en la sociedad, trayendo consigo una convergencia que nos sitúa en un lugar concreto de encuentros con los otros. Se trata del papel que juega la figura del centro comercial.

\section{La figura del centro comercial: espacio de encuentros}

Este espacio medio, bien podría asemejarse al ágora de los atenienses, pensado para el ocio y donde

el orden era impuesto por el comportamiento corporal (...). Estimulaba las personas físicamente, al precio de privarles de una conversación coherente con los demás (...) convirtiendo al ciudadano en esclavo de la mirada. ${ }^{4}$

Resulta curioso cómo los centros comerciales en la ciudad pueden poner de manifiesto, entre otras muchas cosas, el modo en el que el individuo se reconoce a sí mismo en su propio cuerpo y, además, la forma en que se construyen a partir de las concepciones del otro. Este espacio de convergencia y encuentros ha sido construido para la exhibición en la ciudad. Se construye como exposición de maniquíes de plástico como si fueran personas, pero más allá de eso, se muestran modelos de cuerpo y cómo deben ser vestidos siguiendo unos patrones y exigencias sociales concretas.

Así, el centro comercial se configura como uno de los lugares más seguros de la ciudad, donde es posible "mostrarse sin el temor a ser presas del abuso físico o tal vez de un robo. Es el lugar perfecto para el disfrute de la mirada, para el goce de la contemplación." obstante, no podemos rendirnos a ser mero soporte material maleable por las preferencias o gustos del otro. Es necesario aprender a ser nosotros mismos y educarnos en amar y respetar nuestro propio cuerpo tal como es.

3 Jiménez, M. (2008): Espejos y espejismos de una realidad desenfocada, Gaceta Sanitaria, 22 (2), pp. 170. En: http://scielo.isciii.es/pdf/gs/v22n2/imaginario.pdf

4 Sennet, R. (1997): Carne y piedra: el cuerpo y la ciudad en la civilización occidental, Madrid, Alianza, pp. 396.

5 Luna, L.E. (2009): El cuerpo y la ciudad. El cuerpo de la mirada en la ciudad, Posiciones, 2, pp. 101. En: http:// hdl.handle.net/10893/1088 


\section{La moda puede machacar al individuo: re-pensar el cuerpo}

La moda, a través del discurso publicitario, se nutre de miradas hacia un mundo que se desespera continuamente en la búsqueda de una perfección sin formas, de vidas que aún sin ser vividas del todo, ansían perseguir ser quienes no son.

El espacio publicitario se convierte en una lente que desenfoca la realidad, hasta convertirla en un mundo a la medida de los intereses comerciales y no tanto al interés de la propia persona, como sería deseable. Por esta vía, se impone una idea errónea de salud física y mental centrada en la publicidad. La moda vende al espejismo de la esperanza y lo publicita vendiendo sueños y difundiendo miedos. Se incita a la persona a ser mirada y admirada, a ser aceptada y querida, a ser bella, a ser y a no ser, a estar y a no estar, etc.

El cuerpo se convierte en un espacio para la incorporación pero también para la exclusión social. Pero la persona debe de concebirse en su dimensión amplia, es decir, en su globalidad y su sentido total, resistiendo frente a la materialización de los deseos de los otros. Es complejo el abordaje de la percepción de la imagen corporal cuando esta te produce insatisfacción. Sin embargo, no es la apariencia física en sí, sino la vivencia subjetiva del cuerpo o corporeidad lo que altera la imagen corporal, cuya concepción y comprensión debemos cambiar.

Esta reflexión concluye con la necesidad de una urgente llamada a la persona para trabajar en el aprendizaje de nuevos patrones de pensamiento, emociones y comportamientos. De esta manera podremos hacer frente al actual y complejo mundo de las modas, pero desde una óptica reflexiva y consciente de todo lo que supone la adaptación de un cuerpo físico real a un ideal modélico de perfección abstracto, comprendiendo aquello que intenta vender el mercado de la moda.

Se trata de compartir lo que nos produzca bienestar o salud, eliminando los aspectos negativos o dañinos. El beneficio de este tipo de comportamiento será propio, pero a la vez extensible al grupo social en el que se desenvuelve. De esta manera, podremos establecer una incorporación saludable al complicado engranaje que es la adaptación a la sociedad.

Debemos dirigirnos a la tarea de

reconfigurar un universo simbólico y relacional en torno al cuerpo humano que, en vez de ser dominado, secuestrado, mutilado o colonizado pueda despertar la conciencia de una nueva realidad individual social. Tal vez si aceptamos el cuerpo de los otros acabaremos por aceptar nuestros cuerpos con todas sus imperfecciones y limitaciones. ${ }^{6}$

Nos estamos convirtiendo cada vez más en vitrinas que caminan por las calles mientras son ad-miradas por los otros. Por tanto, vale la pena que nos esforcemos en convertir los seres-objeto des-armados y des-almados, en seres-reales con armas para pensar por sí mismos y constituyentes de alma, para no tratar al otro ni a sí mismo como mero producto de venta. El resultado de tal tarea puede ser muy fructífero tanto a nivel personal como colectivo.

6 Villanou, C. (2002): Memoria y hermenéutica del cuerpo humano en el contexto cultural postmoderno, en La memoria y el deseo. Cultura de la escuela y la educación deseada, Valencia, Tirant lo Blanch, pp. 339-376. 


\section{Referencias bibliográficas}

Biedma, J. (2001): Cuerpo fugaz, A Parte Rei: revista de filosofía, 14, pp. 1. En: http://serbal. pntic.mec.es/ cmunoz11/cuerpobied.pdf

Jiménez, M. (2008): Espejos y espejismos de una realidad desenfocada, Gaceta Sanitaria, 22 (2), pp. 170. En: http://scielo.isciii.es/pdf/gs/v22n2/imaginario.pdf

Luna, L.E. (2009): El cuerpo y la ciudad. El cuerpo de la mirada en la ciudad, Posiciones, 2, pp. 101. En: http://hdl.handle.net/10893/1088".

Salaberria, K.; Rodríguez, S. y Cruz, S. (2007): Percepción de la imagen corporal, Osasunaz, 8, pp. 172. En: http://www.euskomedia.org/PDFAnlt/osasunaz/08/08171183.pdf

Sennet, R. (1997): Carne y piedra: el cuerpo y la ciudad en la civilización occidental, Madrid, Alianza, pp. 396.

Villanou, C. (2002): Memoria y hermenéutica del cuerpo humano en el contexto cultural postmoderno, en La memoria y el deseo. Cultura de la escuela y la educación deseada, Valencia, Tirant lo Blanch, pp. 339-376. 
